\title{
LA ENSEÑANZA SUPERIOR NO APRENDE. UNA ESTRATEGIA PARA HACER UNIVERSAL A LA UNIVERSIDAD
}

\author{
O ENSINO SUPERIOR NÃO APRENDE. \\ UMA ESTRATÉGIA PARA TORNAR A UNIVERSIDADE UNIVERSAL
}

\author{
HIGHER EDUCATION DOES NOT LEARN. \\ A STRATEGY TO MAKE THE UNIVERSITY UNIVERSAL
}

Alicia Fernanda Sagüés Silva22

\section{Resumen:}

Los contenidos estudiados en la Universidad son solamente producidos por sí misma, perdiendo todos los saberes de los Pueblos Originarios que las habitan, especialmente en forma de estudiantes incluidos gracias a las propuestas más progresistas. La endogamia académica impide aprender de los estudiantes e incorporar conocimientos y estrategias educativas propias de aquellos Pueblos. Aquí sintetizo 5 años de trabajo a cargo del Seminario de Investigación de la Carrera de Arquitectura de la Universidad de Los Lagos, donde entre el 35 y el $45 \%$ de estudiantes pertenece a algún Pueblo Originario. Los saberes que ellos sistematizan bajo mi estímulo y orientación, son recogidos por sus propios entornos socio-culturales, enriqueciendo además a sus pares. Pero la Universidad aún no los incorpora.

Palabras clave: Estrategias pedagógicas. Aprendizaje universitario. Interculturalidad. Saberes tradicionales.

\footnotetext{
22 Profesora y Licenciada en Historia de las Artes Visuales por la Universidad Nacional de La Plata (Argentina), Magíster en Comunicación Audiovisual por la Universidad Internacional de Andalucía (España) y Dra. en Historia del Arte por la Universidad del País Vasco (España). En 2014 realicé un PostDoctorado en la Universidad Federal de Goiás (Brasil) sobre la imagen audiovisual del Movimiento de Campesinos Sin Tierra. Centro mis estudios en los Pueblos Originarios y Antiguos de América, dedicándome a la educación y la investigación intercultural y audiovisual. Soy miembro activo de la Red Interuniversitaria de Educación Intercultural de Chile(RIEDI), el Observatorio Internacional de Interculturalidad, Inclusión e Innovación Pedagógica con Presidencia(OIIIIPe) con base en Brasil y Capacitadora del Programa ACERCA de la Agencia Española de Cooperación Internacional al Desarrollo (AECID). Desde 2012 soy profesora de la carrera de Arquitectura de la Universidad de Los Lagos, Chile. alisagues@gmail.com/alicia.saguessilva@ulagos.cl+56991896086.https://orcid.org/0000-0003-2645496X
} 


\title{
RevistAleph
}

\section{Resumo:}

Os conteúdos estudados na Universidade são produzidos apenas por ela mesma, perdendo-se todo o conhecimento dos povos Originários que os habitam, principalmente na forma de alunos incluídos graças às propostas mais progressistas. A endogamia acadêmica impede que os alunos aprendam e incorporem o conhecimento e as estratégias educacionais desses povos. Aqui sintetizo 5 anos de trabalho a cargo do Seminário de Pesquisa do Grau de Arquitetura na Universidade de Los Lagos, onde entre $35 \%$ e $45 \%$ dos estudantes pertencem a um Povo Original. Os saberes que, sob o meu incentivo e orientação, sistematizam, são recolhidos pelos seus próprios ambientes socioculturais, enriquecendo também os seus pares. O conhecimento que sistematizam sob o meu incentivo e orientação, é recolhido pelos seus próprios ambientes socioculturais, enriquecendo também os seus pares. Mas a Universidade ainda não os incorporou.

Palavras-chave: Estratégias pedagógicas. Aprendizagem universitária. Interculturalidade. Conhecimento tradicional.

\begin{abstract}
:
The contents studied at the University are only produced by itself, losing all the knowledge of the Native Peoples that inhabit them, especially in the form of students included thanks to the most progressive proposals. Academic inbreeding prevents students from learning and incorporating knowledge and educational strategies of those Peoples. Here I summarize 5 years of work in charge of the Research Seminar of the Architecture Career of the University of Los Lagos, where between 35 and $45 \%$ of students belong to some Native People. The knowledge that they systematize under my encouragement and guidance, is collected by their own socio-cultural environments, also enriching their peers. But the University has not yet incorporated them.
\end{abstract}

Keywords: Traditional knowledge. Pedagogical strategies. University learning. Interculturality.

\section{Introducción}

Si tomamos el origen de la palabra Universidad, tal como lo indica la Real Academia Española, viene del latín universitas que significa universalidad, totalidad (del.rae.es). Pero cuando en el medioevo la Universidad se convierte en la Institución de Educación Superior que recoge, comprueba, valida y transmite los conocimientos, adquiere una cualidad de la que aún no se termina de desprender: se centra en los conocimientos que la Iglesia Católica primero, y los Estados occidentales después, 


\section{RevistAleph}

consideran relevantes de ser conservados, validados y transmitidos; y obviamente todos los demás quedan fuera. Finalmente el círculo que nos moldea se cierra especialmente en el siglo XIX, cuando si bien se estudian otros Pueblos, serán sólo los propios profesionales universitarios occidentales los que construyan endogámicamente esos conocimientos sobre los otros ${ }^{23}$.

A finales del siglo XX cobró mucha fuerza la idea de incluir en estas Universidades, especialmente en América Latina, a estudiantes de Pueblos Originarios ${ }^{24}$, con el propósito de ofrecerles la posibilidad de formarse con excelencia y superar, entre otras, las condiciones de pobreza de sus comunidades.

Ellos han aprendido mucho. Pero los occidentales, las Universidades ¿que hemos aprendido de ellos?

\section{Un racconto}

Quiero comenzar con una aclaración que considero muy relevante: desde luego no me voy a detener aquí a hacer un análisis de la situación de los Pueblos Originarios, pero hay que pensar si realmente la incorporación a las universidades es significativa para la modificación de sus condiciones de vida. Lo que queda para un largo, continuo y dinámico proceso de reflexión colectiva entre los Pueblos Originarios primero y posiblemente luego con los occidentales ${ }^{25}$.

Hace unos 30 años que estamos leyendo cada vez más experiencias educativas que procuran compensar de alguna manera, las atrocidades sufridas por esos Pueblos

\footnotetext{
${ }^{23}$ Esto no significa menospreciar la invalorable labor que sí hicieron las Universidades respecto a los conocimientos fundamentalmente occidentales. Pero esto no es tema de este artículo.

${ }^{24}$ Hablo aquí de Pueblos Originarios, y no de Pueblos Indígenas, porque es la autodenominación que de manera mayoritaria han tomado para toda las instancias oficiales las comunidades con las que yo misma he trabajado durante mis más de 30 años de experiencia, y que además es la denominación que muy especialmente reivindican las comunidades de la macro región sur del sur de América, especialmente Chile y Argentina.

${ }^{25}$ Si tal concepto define algo preciso hoy o no, es una discusión que tampoco voy a dar aquí. Sólo utilizo este concepto desde una cierta coloquialidad, para que se distingan unas culturas de otras. Y si América Latina es o no Occidente, creo que también hay que analizarlo con más profundidad. Sólo diré que yo, como una inmensa mayoría de "mestizos" (otro concepto complejísimo) fuimos educados en las tradiciones occidentales y formamos un corpus muy significativo en América Latina, especialmente en las Universidades.
} 


\section{RevistAleph}

Originarios en los ya más de 500 años desde el paradójicamente llamado "encuentro de culturas"26. Ahora, en el siglo XXI, los países han tomado cartas en el asunto a niveles de Estado y desde las Organizaciones internacionales se han elaborado documentos con el mandato de generar instrumentos para promover tratos más justos y equitativos. Por señalar sólo algunos que afectan el nivel universitario, voy a destacar sólo cuatro:

$\checkmark$ Declaración la III Conferencia Regional de Educación Superior, realizada en Cartagena de Indias, Colombia (2008).

$\checkmark$ Taller Regional sobre Diversidad Cultural e Interculturalidad en Educación Superior en América Latina de Belo Horizonte, Brasil (2009).

$\checkmark$ Iniciativa Latinoamericana por la Diversidad Cultural y la Interculturalidad con Equidad en Educación Superior, de Panamá (2012).

$\checkmark$ Documento de Managua, del Encuentro Regional Aseguramiento de la Calidad en la Educación Superior Intercultural en América Latina y el Caribe (2016) organizado por, entre otros: IESALC-UNESCO, el Fondo para el Desarrollo de los Pueblos Indígenas ${ }^{27}$ de América Latina y El Caribe, el Programa Universidad Indígena Intercultural (UII), el Consejo Nacional de Universidades de Nicaragua y la Red de Universidades Indígenas, Interculturales y Comunitarias de Abya Yala.

Señalar también la propia creación por parte de la UNESCO del Observatorio de Diversidad Cultural e Interculturalidad en Educación Superior, encargado de investigar y dar difusión de estas recomendaciones, las que han sido compiladas especialmente bajo la coordinación de Daniel Mato (2008, 2012, 2018). Lamentablemente este Observatorio dejó de formar parte del programa regular de UNESCO-IESALC, por decisión de su Consejo de Gobierno, en septiembre de 2019 (https://www.iesalc.unesco.org/observatorio-de-diversidad-cultural-einterculturalidad-en-educacion-superior/). Una auténtica pérdida.

${ }^{26}$ Denominación que ha merecido y merece aún, un debate que no sé si tendrá fin.

27 Entiéndase que aquí, como en otros casos, esta denominación es la que ha establecido la institucionalidad firmante, no yo como autora. 


\section{RevistAleph}

Sin embargo, más allá de las declaratorias y compromisos, deberíamos analizar el impacto real de las medidas y acciones concretas realizadas al interior de las diferentes Universidades de los distintos países. Para ello estoy en pleno proceso de interpretación de los resultados de una investigación que he llamado "Cartografía de la Educación Intercultural en Iberoamérica", con la colaboración de destacados docentes e investigadores de distinta instituciones de Brasil, Chile, Argentina, Ecuador, México, Colombia y, Panamá en nuestro continente, y Granada, Las Palmas, Barcelona, Santiago de Compostela y Vigo en España.

Y preliminarmente, los datos recogidos indican que, más allá de las diferentes situaciones existentes en América y Europa, las Universidades incorporan a la diversidad cultural de sus propios territorios y de otros, pero no aprehende de ellas. Es decir, los conocimientos y estrategias educativas especialmente de los Pueblos Originarios no se incorporan y desde luego no se transmiten, de forma sistemática y general en actividades curriculares universitarias concretas.

Es significativo que la perspectiva de lo intercultural en las Universidades, comienza en las Carreras de Pedagogía para los niveles básicos de los sistemas educativos. A grandes rasgos, y porque tampoco es el tema de este artículo, si bien en esas instituciones de educación superior se ocupan de optimizar la inclusión de los grupos de culturas diferentes a la dominante, y de revalorar las lenguas de estos Pueblos, dicha preocupación no se traslada a los universitarios que siendo de los Pueblos Originarios están estudiando para ejercer luego una educación intercultural o una educación al menos bilingüe.

Algunos casos muy elaborados y con resultados significativos pueden señalarse en México, como los diferentes programas desarrollados por Luis Enrique López (2001 y 2004), que por supuesto habrá que seguir discutiendo, o las Universidades Interculturales, cuyo análisis recomiendo a través de la lectura de Lehmann (2014). O la significativa experiencia de la Universidad Veracruzana también de México, en el equipo encabezado por Gunther Dietz (2008 y 2019). Y a su vez destacar las múltiples experiencias en diferentes países de América Latina, compiladas por Daniel Mato en diferentes publicaciones como las ya citadas. 


\section{RevistAleph}

También hay experiencias puntuales muy reveladoras, en las que la pedagogía no es el centro, e incluso no es parte de las mallas curriculares de las Carreras ni de los profesionales que las están implementando, como es la experiencia que se desarrolla a partir del Instituto de Estudios Socioambientales de la Facultad de Geografía de la Universidad Federal de Goiás y que tuve el honor de experimentar personalmente en un post-doctorado.

Pero muchas veces, en las propuestas y acciones realizadas, no hay una verdadera interculturalidad (entendida sintéticamente como la interacción respetuosa de entre las diversidades), sino más bien una multiculturalidad jerarquizada (donde si bien se reconoce la diversidad, hay una o unas culturas dominantes sobre otras) que a veces, además, contiene tintes paternalistas. Tenemos muchos ejemplos bien intencionados, pero a mi juicio están mal enfocados, como por ejemplo el de la Universidad de Chile, que ofrece cursos del idioma de los Mapuche para profesores (lo que sin duda, a mi parecer, es un paso en la buena dirección). Pero ¿cuándo vamos a aprender nosotros de ellos? ¿Cuándo serán los miembros de los Pueblos Originarios los que den cátedras en la Universidad para que los occidentales nos enteremos de cómo conciben el universo, la salud, el habitar, la "estética", el lenguaje, las matemáticas? Espero que pronto.

\section{Mi enfoque teórico}

Pero, a qué me refiero con interculturalidad? En este tiempo de paradigmas autorales, me corresponde asumir que hace tiempo que he adoptado como definición (utópica, si se quiere) que la interculturalidad es la interacción entre dos o más culturas de un modo horizontal y sinérgico, lo que implica que ninguno de los grupos se encuentra, se siente o se piensa por encima del otro, y donde tampoco ninguno se confunde con el otro.

Y hablo de utopía como dijo mi querido Maestro Fernando Birri en una conferencia: "La utopía está en el horizonte. Camino dos pasos, ella se aleja dos pasos y el horizonte se corre diez pasos más allá. ¿Entonces para qué sirve la utopía? Para eso, 


\section{RevistAleph}

sirve para caminar" ${ }^{28}$. Y como a aquella interculturalidad apuntamos... nos queda aún mucho camino por recorrer.

A partir de mis más de 30 años de aprendizaje y trabajo intercultural, y como resultado directo de mis últimos 9 años de docencia universitaria ${ }^{29}$ e investigación, he generado una propuesta que asumo compleja y multidimensional, y que he denominado Educación Intercultural Recíproca.

La palabra recíproco significa acción o sentimiento de uno hacia otro, que el otro le corresponde de igual modo, en la misma medida. Recíproco es sinónimo de mutuo. Pero lo más interesante aquí es que esta propuesta se define mejor a partir de las matemáticas. Existe un número recíproco: si a un número lo multiplicamos por su recíproco, siempre obtendremos 1 por resultado. Por ejemplo: el número recíproco de 2 , es $1 / 2$, por lo que $2 \times 1 / 2=1 \ldots$ la magia de los números nos muestra la unidad en la reciprocidad. No importa cuán grande sea el número, multiplicado por su recíproco, siempre dará 1! Esto da de lleno en mi idea de interculturalidad, la de multiplicarnos para la unidad, la unidad de la diversidad como un potenciador de cada uno. Por supuesto, esta unidad devenida de la multiplicación, se da en un contexto territorial determinado, que puede ser desde una sala de clases hasta un país. El límite de dicho territorio quedará en manos de los actores participantes.

Hay que detenerse aquí un momento, en el tema del territorio, porque como decía, la unidad de la interculturalidad se da allí. Y no me refiero a desarrollar un análisis epistemológico ni evolutivo del concepto de territorio. Sino sencillamente a dimensionar la variable espacial en la comprensión de este constructo social en el que habita una diversidad de realidades y entendimientos, legislaciones e imaginarios, sueños y sentimientos sobre un mismo territorio. Pensar que en relación con el campo de acción de la interculturalidad debemos "limitarlo" para tener la dimensión real de la complejidad de nuestra situación.

\footnotetext{
${ }^{28}$ Como esto fue luego publicado y comentado muchas veces por Eduardo Galeano, se le adjudica a él, quien no se cansaba de repetir que la frase la acuñó Birri.

${ }^{29}$ Quiero aprovechar aquí para agradecer a las diferentes Jefaturas de la Carrera de Arquitectura de la Universidad de Los Lagos, por darme total libertad de cátedra y permitirme "experimentar" esta propuesta.
} 


\section{RevistAleph}

En mi experiencia, la aplicabilidad de mi propia propuesta se resume a mis diferentes salas de clase, pero ellas están en un contexto más amplio, que es la propia Universidad y está dentro de un entorno regional, que es muy diferente a otras Regiones de Chile. Partamos del acuerdo que el conocimiento que tengamos de nuestros "laboratorios o campos de acción", el acuerdo que logremos con sus integrantes, los apoyos que seamos capaces de conseguir, etc., condicionarán el alcance de la propia interculturalidad.

Obviamente, estoy convencida que cuando hablamos de interculturalidad y educación, estamos hablando básicamente de valores, es decir, de la transmisión, en términos de Debray (1997), de principios especialmente de respeto, equidad, empatía y solidaridad que deben regir la concepción completa (compleja y dinámica) de todo los procesos, sus actores, los ambientes, los ritmos de dicho quehacer social, los contenidos y por supuesto el carácter de las inter-relaciones de todos los individuos y comunidades, en sus propias dinámicas.

En Occidente, como sucede en todas las culturas, construimos un universo entero dentro de nuestros propios paradigmas, capacidades o intereses. Y aunque éstos se transformen en el tiempo, nos limitan o francamente nos impiden comprender la construcción de otros universos con lógicas de pensamientos diferentes. En el caso particular de América, como "somos los vencedores" de las batallas bélicas e ideológicas "contra" los Pueblos Originarios, los occidentales nos hemos creído y les hemos hecho creer que el "conocimiento científico" que hemos armado ${ }^{30}$ como la forma de generar nuestros conocimientos, es la única forma de conocer, de aprender y de descubrir verdaderamente cómo funciona el mundo. Quienes estamos ocupados por el trabajo intercultural, dudamos de esto lo suficiente como para pensar sistemáticamente en ello... aunque aún no sepamos muy bien cómo podemos hacer para salir de nuestra propia jaula.

Pero tampoco me voy a extender aquí en esto. Sólo voy a señalar que dicha reflexión generó la necesidad de crear la investigación ya indicada, esa Cartografía en la que también continúo trabajando.

\footnotetext{
${ }^{30}$ Espero se aprecie el doble sentido de esta palabra aquí.
} 


\section{RevistAleph}

Lo que en este artículo quiero compartirles, es una experiencia puntual que estoy segura puede reproducirse en muy diferentes contextos, siempre y cuando todos los protagonistas estén dispuestos a sacudir su confort mental e incorporar los saberes, lógicas y mecanismos de aprendizaje que los Pueblos Originarios han tenido por siglos, y que aún sobreviven, permitiéndonos descubrir universos diversos, con la intención de construir una auténtica interculturalidad.

\section{Mi experiencia en proceso}

Como indicaba antes, luego de un largo recorrido por Iberoamérica, hace 9 años que me radiqué en el sur de Chile. Desde 2012 hago clases en la Universidad estatal de la Región de Los Lagos y desde 2014 me hice cargo de los cursos de investigación de la Carrera de Arquitectura, en donde he desarrollado esta experiencia que les comparto aquí, y algunas reflexiones que me ha generado.

Para entender lo que propongo, es necesario hacer, como en todo trabajo sobre interculturalidad y educación, un reconocimiento de la población, que aquí sintetizaré por medio de las estadísticas oficiales. Según el censo 2017 en Chile, sobre una población aproximada a los 17.5 millones de habitantes, cerca de 2.2 millones se reconocen pertenecientes a algún Pueblo Originario (12,8\% del total), y es destacable que un porcentaje semejante habita en zonas rurales. Recordemos que el dato sobre la identidad cultural de las personas se basa en el principio del auto-reconocimiento; por lo que no sabemos cuánto inciden la autoestima y el estigma social en dicho proceso y en los resultados mismos del censo.

Pero como Chile es un país muy extenso, con unos de $4.300 \mathrm{~km}$ de longitud, la diversidad interna es muy amplia, en todos los sentidos de la palabra. Particularmente la Región de Los Lagos cuenta con una población cercana a los 830.000 , en la que más del $28 \%$ se reconoce como perteneciente a un Pueblo Originario y algo más del $26 \%$ del total de la población, habita en la zona rural. En este contexto encontramos la Universidad de Los Lagos que es la única estatal o pública de la Región. Según los datos entregados por la propia institución, en ella tenemos aproximadamente un $80 \%$ 


\section{RevistAleph}

estudiantes que es primera generación de universitarios de su familia, un 70\% proceden de la Educación pública (la peor valorada en Chile), un 60 \% socioeconómicamente "vulnerables", un $50 \%$ de zonas rurales, y entre el 45 y el $35 \%$ pertenecientes o "descendientes" de Pueblos Originarios. Es decir, al interior de la Universidad, tenemos un porcentaje mayor de población originaria que la presente en el seno de la misma sociedad. Tema que merece una investigación profunda aparte.

En mis clases de los cursos de investigación los porcentajes señalados para la Universidad se repiten. Por otro lado, e independientemente de las asignaturas que uno tenga a cargo, creo que hay que tener una visión lo más amplia posible del contexto educativo en general y en particular de los grupos humanos con los que trabajamos en las salas de clase.

Por eso es necesario contextualizar, incluso a uno mismo. $Y$ es aquí donde quiero hacer un paréntesis al respecto. Porque puede ser que se entienda mejor mi propuesta, si les comparto mi formación: soy historiadora del arte de profesión, y antes que eso, Maestra de Dibujo. Comencé a estudiar artes a los 10 años y aún sigo aprendiendo, porque estoy convencida que es desde lo sensible, lo artístico, lo simbólico, lo estético, podemos encontrar respuestas más profundas, más amplias y más sinceras para la comunicación respetuosa con los demás. Por eso, a partir del conocimiento adquirido, he ido desarrollando una estrategia de valorización y recuperación de los saberes de las comunidades y familias de procedencia de mis estudiantes, fundamentalmente lo que más se manifiesta en mis salas, en relación a las identidades originarias, es vergüenza. Pero algunos otros estudiantes por sus procedencias, con una educación formal que deja mucho que desear, empobrecidos, inmigrantes o menospreciados por diferentes razones, sufren una similar estigmatización, y pueden ser igualmente gran fuente de conocimientos.

Como ya dejé dicho, me cansé que sólo tomáramos los saberes sobre los Pueblos Originarios, traducidos en contenidos, investigados y sistematizados sólo por los profesionales universitarios occidentales u occidentalizados ${ }^{31}$. Mi acercamiento a los Pueblos Originarios y luego a las culturas populares, ha sido a partir de mi curiosidad

\footnotetext{
${ }^{31}$ Otro concepto para otra discusión.
} 


\section{RevistAleph}

vital, que siempre me moviliza, pero comenzó a partir de los relatos de mi abuela, una inmigrante navarra en la Patagonia argentina, que convivió por décadas con los nativos de allí y de quienes aprendió mucho. Ella me transmitió el sentimiento de admiración que tengo por ellos. Sin querer convertirme en parte de esos Pueblos, de esas comunidades, me he movido siempre con el respeto como principio fundamental, procurando aprehender (de hacer mío sus saberes, de interiorizarlos, no sólo recordarlos). Y eso intento transmitir en mis clases, que funcionan más como reuniones de reflexión o talleres de pensamiento que como cátedras tradicionales.

Hay que tener en cuenta en mi caso, que Chile es un país y Los Lagos en especial, una Región que aún conserva una estructura fuertemente clasista, e históricamente la Universidad (aunque tuvo un extenso período de gratuidad) se destacó desde la última dictadura militar, como el espacio de reforzamiento de la "superioridad" de las clases con más recursos económicos. En los últimos años y gracias a una serie de ayudas, becas y últimamente un nuevo sistema de gratuidad para los grupos de menos recursos económicos, éstos pueden acceder a estudios superiores. Así cerca del $80 \%$ de nuestros estudiantes pueden convertirse en la primera generación de

profesionales universitarios de sus familias. Por esos antecedentes entonces, su autoestima en general es muy baja. Ellos suelen, además, negar o renegar de sus orígenes sociales y/o culturales, y yo, francamente desde el lado más humano de la educación que se manifiesta en la empatía, no quiero que sigan así.

Es importante señalar aquí, que en este momento de pandemia y por la carga que implica para mis estudiantes estar estudiando remotamente, no he querido molestarlos con la responsabilidad que implica la participación en un artículo como este. Por ello estas palabras se basan fundamentalmente en mis reflexiones, desde mi mirada de profesora/investigadora. Pero de todos modos les he mantenido informados y me han respaldado en lo que escribo, lo que agradezco infinitamente.

Por otra parte, tal vez por mis propios orígenes y mi propia experiencia vital, considero que los resultados de investigación más significativos se obtienen cuando hay una motivación visceral para desarrollar dicho proceso. Sabiendo lo difícil que es incorporar los hábitos de investigación para quienes están ya habituados a diseñar 


\section{RevistAleph}

espacios, para mis cursos de investigación elaboré una estrategia uniendo ambos desafíos: buscar un tema y/o un caso que movilice a mis estudiantes desde lo más profundo de su ser, para que sea más fácil adquirir esos nuevos hábitos y también para que pongan en valor sus procedencias, ancestros e intereses personales más íntimos.

Para ellos comienzo mis clases presentándome desde mi historia personal, homologando un proceder que aprendí de los Mapuche en Argentina. Luego les pido a los estudiantes que se presenten, que cuenten sus orígenes y después, como estamos en una zona de gran presencia Mapuche-Huilliche (así como de otras culturas ninguneadas), les aconsejo a mis estudiantes que recurran siempre a sus raíces para pensar lo que se les propone desde las asignaturas, para que todos aprendamos de todos e incluso para implicar en sus aprendizajes a sus familias y comunidades. Claro está que quienes no tienen ascendencia Originaria se presentan de igual modo, y con ellos muy especialmente me enfoco en abrir sus mentes a la valoración de quienes sí van a trabajar con sus ancestros y comunidades por un tema identitario fuerte. Procuro que todos igualmente, trabajen desde un tema que les es emotivamente significativo y desde sus entornos y comunidades, porque hay, como ya indiqué, mucho para aprender, en todos lados.

Gracias al hecho de que cuento con grupos pequeños, de no más de 15 estudiantes (que por otra parte considero número cercano al ideal), puedo animarlos a incursionar en esos temas que nacen muchas veces, en sus infancias y sus relaciones familiares más íntimas. Una vez elegido y delimitado el tema y el caso, comenzamos a compartir los avances de las investigaciones entre todos, de modo que cada uno de ellos forme parte también de las investigaciones de los demás. Así se acompañan durante todo el camino, aprendiendo los unos de los otros, y yo con ellos.

Obviamente, si bien deben aprender todo lo previsto en el Programa de estudios que asimismo incluye la importancia de los "datos duros" y la lógica del pensamiento científico occidental a partir de las lecturas académicamente relevantes, con su devenir de paradigmas, me interesa que comprendan también las lógicas de pensamiento y acción de sus abuelos o de sus comunidades. A todos les incito a que 


\section{RevistAleph}

escuchen la música, vean otras producciones artísticas ${ }^{32}$, que lean o conozcan sus mitos e historias, busquen y rebusquen en los álbumes de fotos familiares, que analicen desde la propia observación los emplazamientos en sus territorios, aunque vayan a trabajar sobre el interior de las casas. Si algo he aprendido de los tantos años de convivencia con diferentes Pueblos Originarios, es que sus miradas (sin generalizar) son, al menos, menos fragmentarias que la occidental. La relación de todas las partes, que incluso se intenta desde la hermenéutica, se queda corta ante los lazos que se tejen en los universos por ellos construidos, o por ellos comprendidos... quién sabe qué Universo es el que realmente existe?

La misma fragmentación que hemos aplicado, compartimentando las Facultades y Carreras en las Universidades del mundo, nos impide tener un entendimiento profundo de los saberes de los Pueblos Originarios, pero también de la compleja realidad en la que todos estamos inmersos. De las peores experiencias en este sentido, pienso en algunos proyectos de forzadísimas carreras sobre "lenguas originarias" o el mismo hecho, ya señalado, de colocar sólo como datos sus características. De este modo, y con el mantenimiento de esas prácticas, la Universidad se pierde, en su además burocratizada estructura, y en su insistencia en la enseñanza más que en el aprendizaje, esas formas de interiorizar, de aprehender y "descubrir" dichos saberes.

Volviendo a mis clases que se realizan en Puerto Montt, cuando el clima extremadamente lluvioso nos lo permite, salimos a los patios, o incluso a la calle; mis estudiantes trabajan casi más en terreno que en las salas de clase; y si bien leen mucho (cosa que no solían hacer antes, y constituye un destacado resultado en el ámbito de los hábitos de estudio), hablan también mucho más y con mayor profundidad con sus compañeros, sus profesores y sus mayores, y contemplan... ya no sólo observan, lo que es también una nueva "estrategia" de adquisición de conocimiento. Quiero señalar además, que leen mucho porque han comprendido que los textos, en definitiva, son los saberes de otras personas que sólo pueden dialogar con ellos por ese medio; sus

${ }^{32}$ Concepto que no voy a discutir aquí, porque ya lo hice mucho, pero podría resumir en que vean pinturas, esculturas, cesterías, tejidos, piezas de orfebrería, etc.. 


\section{RevistAleph}

reflexiones, sus experiencias, sus dudas, sus miradas, son para ser conversadas, no para acatarlas ni memorizarlas, sino para ayudarnos a crecer. Y eso hacen!

Así hemos logrado (y digo hemos porque el trabajo es también entendido como colectivo), sistematizar esas observaciones, esas charlas, obteniendo resultados también en lo que se refiere a la construcción del conocimiento mismo, como función de los cursos de investigación: relacionando el saber sobre las estrellas con la forma de orientar las casas de las comunidades Huilliche; hemos descubierto las técnicas de corte de la madera para la construcción de palafitos en Chiloé; la "evolución" de las viviendas ancestrales hasta la casa actual regularizada en sectores rurales descendientes de Pueblos Originarios; la ocupación y significación de los espacios ceremoniales en celebraciones mestizas, etc.. Hemos aprehendido también muchísimo sobre cómo vivimos a partir de la lógica occidental dominante.

La ventaja de trabajar con y desde los estudiantes en incorporar los saberes y estrategias de aprendizaje de los Pueblos Originarios es clara, especialmente cuando son primera generación universitaria, aún no están tan "contaminados" podríamos decir, con la rígida estructura del pensamiento científico occidental. Han aprendido mucho de sus resultados, y también de la aplicación del proceso, de la construcción de conocimiento que se les pide especialmente en los cursos de investigación.

Por otro lado, hay que considerar que son ellos, los estudiantes con sus familias y comunidades, quienes más conforman el territorio, porque como en muchos sitios, los profesores no necesariamente somos todos de la Región donde impartimos clases. Es significativo por su parte que la emoción causada en las familias y/o comunidades, por el hecho mismo que uno de sus miembros esté en la Universidad, facilita para llegar a los saberes que los estudiantes están buscando. Obviamente yo no pido que "estudien a sus mayores", sino que aprendan de ellos, con ellos, que es muy diferente. Y esta insistencia se impone al recabar de los propios estudiantes un porcentaje muy bajo de interés, respeto y admiración por los saberes de sus mayores. Por suerte o por tozudez, siempre hemos tenido los mejores resultados, porque está incluido el orgullo que los estudiantes sienten, al avanzar en sus procesos de investigación, ante el reconocimiento de sus trabajos y la valoración que entre todos hacemos de los saberes locales, sean 


\section{RevistAleph}

Originarios o no. Algo muy importante es la buena aceptación que tienen tanto los procesos como los resultados de estos cursos: los conocimientos generados por los estudiantes son considerados verdaderos descubrimientos por sus profesores$\operatorname{arquitectos}^{33}$, y son ellos quienes agradecen este trabajo. Como también lo agradecen los colegas pedagogos, artistas, arquitectos asistentes a los Congresos donde he ido presentando en los últimos cinco años, los resultados de mi práctica de la Educación Intercultural Recíproca ${ }^{34}$. De más está decir que entre los propios compañeros de estudio, esta metodología se retroalimenta y fortalece también el interés por los conocimientos de todas las procedencias.

Más importante aún, si cabe es que desde hace un par de años al interior de mi Cátedra de Seminario de Investigación los trabajos de estos estudiantes, tanto sus procesos y como sus resultados, son consultados por las siguientes promociones, para nutrir sus nuevo trabajos. De este modo, cada investigación es ampliada año tras año desde nuevas miradas, con más aportaciones, sobre otros casos. Y este año 2020, con la necesidad de nuevas formas de aprender e investigar, esta modalidad de "interconsulta" entre los propios estudiantes, se ha extendido a Taller de Título, lo cual demuestra aún más la fertilidad de la estrategia propuesta. Fuera de lo que pudiera pensarse, que referenciarse entre ellos produce un proceso endogámico, esto está desarrollando una espiral de crecimiento continuo que espero pronto pueda ser ampliada hacia trabajos semejantes de otros Cursos, otras Carreras y otras Universidades. La mirada intercultural convierte al saber en infinito...

Se trata pues de aprender a aprender de nuevo, a aprender distinto, a aprehender en diversidad, a validar que el saber de todas las culturas es equivalente al nuestro (sea cual fuere el nuestro) y muchas veces, puede ser más preciso y más efectivo. Aún nos falta colocar esos saberes en el universo de las Universidades. En eso estamos trabajando. Por eso también es este artículo.

${ }^{33}$ Cabe señalar que entre el equipo docente de la Carrera no hay profesores que se identifiquen como de Pueblos Originarios.

${ }^{34}$ En las Referencias se indican algunas publicaciones disponibles al respecto. 


\section{RevistAleph}

\section{Consideraciones finales}

El trabajo es muy largo, complejo y duro. Todos sabemos del encarnado status quo de las Universidades, lo endogámico de nuestro pensamiento y el miedo atávico que genera perder el control de la producción de conocimientos. Pero para mí, todos estos son estímulos, desafíos, energías para continuar.

Obviamente lo que propongo, para ser aplicado sistemáticamente en forma integral, debe ser discutido ampliamente, pero no sólo dentro del estamento académico, sino consensuadamente con los estudiantes, y por supuesto, con las comunidades. Porque implica algo más profundo que un simple cambio de paradigma universitario. Estoy clara también que no soy yo quien pueda ni deba hacer esta transformación sola. Esto es una decisión política si se quiere, de un conjunto de personas, que ojalá, sea más grande cada vez.

Algunas de las muchísimas propuestas que requieren una reflexión profunda por parte de los miembros de las Universidades que realmente quieran transformarse en "universales", son por ejemplo: las variables tiempo y tiempos, espacio y espacios, recursos, métodos, modalidades de construcción del conocimiento, estrategias de aprendizaje... y orgullos. Los diálogos horizontales entre los saberes, el respeto mutuo, que por muy diversas razones no es fácil conseguir a veces, pueden incluso aplicarse cuando no existe en el medio académico, en el territorio en el que nos encontremos, la diversidad cultural tan amplia que tenemos en América. Pero aun así, las cada vez más dinámicas y numerosas migraciones (lamentablemente por lo general por situaciones de guerras y hambrunas), han convertido a todo el planeta en un lugar de diversidad cultural, como lo ha sido siempre, aunque no se le reconociera. $Y$ esas diversidades, antes o después, llegan a las salas de clase de las Universidades.

¿Y por qué pienso aquí sólo en la educación superior? Estoy convencida que las Universidades son el mejor lugar para generar esta transformación en primera instancia, porque se supone que es aquí donde están las personas más cualificadas y más dedicadas a la reflexión crítica de sus propios saberes. Porque tenemos tiempos pagados 


\section{RevistAleph}

para un trabajo como el que es necesario y porque formar profesores y profesionales con la sensibilidad necesaria hacia el saber universal de verdad, los saberes de todos, permitirá tener un impacto mayor, más rápido y profundo en las sociedades donde ejerzamos el cambio.

Llevamos sobre nuestros hombros el karma del colonialismo, incluso cuando intentamos des o de-colonizarnos, seguimos anclados al concepto y arrastrando el lastre hasta las últimas consecuencias, aun a veces $\sin$ saberlo 0 , sencillamente $\sin$ reconocerlo, o nos enredamos en los conceptos y desechamos las acciones sobre la realidad. Esto no puede seguir pasando en Educación Superior. Necesitamos Universidades universales ya.

Ahora será cuestión de trabajar en ir conversando e incorporando paulatinamente estas estrategias en otros lugares, cuyos profesores se interesen por saber lo que hay más de lo que dicen los libros y sus pares.

\section{Referencias:}

DEBRAY, R. Transmitir. Buenos Aires: Manantial. 1997.

DIETZ, G. y MATEOS CORTÉS, L. Interculturalidad y educación intercultural en México. México: SEP. 2011.

DIETZ, G. y MATEOS CORTÉS, L. ¿EI racismo como problema, la interculturalidad como solución? El caso de la Universidad Veracruzana en México. En: Apuntes para la erradicación del racismo. Buenos Aires: UNESCO-UTREF. 2019.

INSTITUTO NACIONAL DE ESTADÍSTICAS. Síntesis de resultados. Censo 2017. Santiago: INE. 2018.

LEHMANN, D. Convergencias y divergencias en la educación superior intercultural en México. Revista Mexicana de Ciencias Políticas y Sociales, Año LX (223) 133-170. Universidad Autónoma de México. 2015.

LÓPEZ, L. E. La cuestión de la interculturalidad y la educación latinoamericana. Séptima Reunión del Comité Regional Intergubernamental del Proyecto Principal de Educación en América Latina y el Caribe, UNESCO. 2001.

LÓPEZ, L. E. y SICHRA, I. La educación en áreas indígenas de América Latina: balances y perspectivas. En: HERNÁlZ, I. Educación en la diversidad: experiencias y desafíos en la educación intercultural bilingüe. Buenos Aires: IIPE-UNESCO. 2004. 


\section{RevistAleph}

MATO, D. (Coord.). Diversidad Cultural e Interculturalidad en Educación Superior. Experiencias en América Latina. Caracas: IESALC-UNESCO. 2008.

MATO, D. (Coord.). Educación Superior y Pueblos Indígenas y Afrodescendientes en América Latina. Normas, políticas y prácticas. Caracas: IESALC-UNESCO. 2012

MATO, D. (Coord.). Educación Superior y Pueblos Indígenas y Afrodescendientes en América Latina. Políticas y experiencias en inclusión y colaboración intercultural. Sáenz Peña: Universidad de Tres de Febrero. 2018.

SAGÜÉS SILVA, A. Nuevos espacios para antiguos saberes: la formación universitaria en la interculturalidad de la Arquitectura y las Artes. III Congreso Internacional de Educación e Interculturalidad (RIEDI). Universidad Tarapacá, Arica, Chile. 2015.

SAGÜÉS SILVA, A. Estrategias para la visibilización y puesta en valor de la cultura local desde la Universidad. Seminario de Estudios Culturales, Postgrado Latinoamericano de Estudios Culturales y Literarios. Universidad de Los Lagos. Santiago, Chile. 2016.

SAGÜÉS SILVA, A. Experiencias interculturales en la Universidad: más allá de lo establecido. IV Congreso Internacional sobre Educación e Interculturalidad (RIEDI) Universidad Católica de Temuco, Chile. 2017.

SAGÜÉS SILVA, A. Una cartografía para la Educación Intercultural Recíproca: la unidad enriquecida por la diversidad. En: ALCÁNTARA, M., GARCÍA MONTERO, M. y SÁNCHEZ LÓPEZ, F. (Coords.) 56 Congreso Internacional de Americanistas. Educación. (pp. 1045-1055). 2018.

SAGÜÉS SILVA, A. Construyendo territorio e identidad: experiencias de investigación en pregrado. Seminario de Arquitectura Latinoamericana (17 SAL). Universidad Católica de Ecuador y Red Interuniversitaria de Estudios Urbanos de Ecuador. Quito, Ecuador. 2018 (Actas en prensa).

SAGÜÉS SILVA, A. Valorar la herencia: estrategias de promoción de la investigación patrimonial. VIII Congreso de las Comunidades del Patrimonio. Chonchi, Chiloé, Chile. 2019.

SAGÜÉS SILVA, A. Formación de Arquitectos para la sociedad intercultural. V Congreso Internacional de Educación e Interculturalidad (RIEDI). Santiago, Chile: Universidad de Chile (Actas en prensa). 2020.

SAGÜÉS SILVA, A. Investigar identidad: arquitectura para territorios interculturales. IX Encuentro de Docentes e Investigadores de Historia de la Arquitectura, el Diseño y la Ciudad, Organizado por Instituto de Investigación Historia, Teoría y Praxis de la Arquitectura y la Ciudad, Facultad de Arquitectura y Urbanismo, Universidad Nacional de La Plata y el Instituto de Arte Americano “Mario J. Buschiazzo", Universidad de Buenos Aires. 2020.

UNESCO. Declaración de la III Conferencia Regional de Educación Superior, realizada en Cartagena de Indias, Colombia (2008).

Data do envio: $27 / 08 / 2020$

Data do aceite: $21 / 10 / 2020$. 